\title{
Energy-Saving technology of axial flow fan used in air- conditioning system
}

\author{
Chan Lee ${ }^{\mathrm{a}}$, Hyo Sang Kim ${ }^{\mathrm{a}}$, Hwan Geol Yeo ${ }^{\mathrm{b}}$ \\ ${ }^{a}$ Dept. of Mech. Eng., Univ.of Suwon, Bongdam, Hwaseong 18323, Republic of Korea \\ ${ }^{b}$ KoreaAmass, Daegot, Gimpo 10038, Republic of Korea
}

\begin{abstract}
The present study provides an energy-saving design method of axial flow fan used in air-conditioning system and verifies its design results through comparison with test results. The present design method employs combined vortex design concept in constructing three dimensional fan blades, and the performance analysis of designed fan is made by the through-flow method with pressure loss and flow deviation distribution models along swept blade height. For the verification of the present design method, a new fan model is designed and manufactured, and its performances are predicted and compared with actual test results. The comparisons between the present prediction and the test results show very good agreements in the aspects of static pressure, power and efficiency. Furthermore, the present design method is shown to give less power consumption than conventional fan model.
\end{abstract}

Keywords: Axial flow fan; combined vortex design; through-flow analysis; reduction of power consumption

\section{Introduction}

Axial flow fans are widely used in low-pressure air handling systems such as air-conditioning, ventilating or cooling equipment. However, because axial flow fans are turbo-machines consuming a lot of electrical power energy in their applications, there are growing concerns on the fan design with less power consumption in many fan manufacturers and users. In general, axial flow fan is composed of multiple fan blades with three dimensional curved surfaces, and its performances are severely dependent on the blade surface geometry. 3-D fan blade geometry design is made by combining cascade theory and vortex design concept to determine blade element's camber and thickness and to stack the blade elements along blade span height.

Free vortex design concept has been widely used in fan design practice but has the fundamental shortcomings of severe blade twisting causing fan performance deterioration [1]. For this reason, combined vortex design concept is recently being applied for reducing blade twisting as well as improving performance. However, in the fan design step with combined vortex design concept, it is very difficult for fan designers to predict the effects of combined vortex design concept on fan performance parameters, so they call for the reliable and simple performance prediction method of combined vortex designed fan [2].

Therefore, in the present study, a computer program for fan design and performance prediction is developed and introduced. The present computer program is composed of design and prediction parts. At 3-D fan blade geometry design step, the present method designs curved blade surface shape with the use of combined vortex design concept, and at next fan performance prediction step, its analysis is conducted by the through-flow method with pressure and deviation models. In order to verify the design reliability and the prediction accuracy of the present method, the present method is applied to different fan design

*Manuscript received November 20, 2016; revised January 20, 2017.

Corresponding author. Tel.: +821042721487; E-mail address: clee@ suwon.ac.kr

doi: $10.12720 /$ sgce.6.2.114-118 
cases and its prediction results are compared with their test results.

\section{Fan Design and Performance Prediction Methods}

\subsection{Fan design method}

In constructing the blade geometry, the present method firstly determines blade angle distribution along blade span height by using the following equations [2] as

$$
\begin{aligned}
& \tan \beta=\frac{U-V_{\theta}}{V_{x}} \\
& V_{\theta}=\left[\begin{array}{rr}
\text { ar }-\frac{b}{r} & \text { before }- \text { rotor } \\
\text { ar }+\frac{b}{r} & \text { after }- \text { rotor }
\end{array}\right]
\end{aligned}
$$

where $\beta, U, V_{x}$ and $V_{\theta}$ represent blade angle, blade rotation speed, axial and tangential velocities of air. Here, the equation (2) stands for combined vortex design if $a$ and $b$ are non-zero and free vortex design if $\mathrm{a}$ is zero. In addition, $\mathrm{V}_{\mathrm{x}}$ and $\mathrm{U}$ can be deduced from the design flow capacity and the rotational frequency as fan design requirements.

After the determinations of blade angles at each blade element using the equations (1) and (2), the present method constructs the camber lines and the blade thickness distributions of blade elements, and stacks the section designs of blade elements with the axis of the center of gravity along blade span height to form 3-D curved fan blade surface [2].

\subsection{Fan performance prediction method}

Once fan blade geometry is determined, for fan performance prediction, the present method analyses steady-state and axisymmetric fan flow field by the through-flow modeling on pitch-averaged and hub-totip flow surface where several streamlines are set along blade span. The through-flow method is applied to the streamlines and calculates flow field data such as flow velocity, flow angle and pressure at fan blade outlet through solving equation (3) with Euler work equation, flow deviation and pressure loss models. Detailed solution procedure of the through-flow method is described in Novak's paper [3].

$$
\begin{aligned}
& \frac{d V_{m}^{2}}{d r}+2 \sin ^{2} \beta\left[-\frac{\sin \phi}{V_{m}} \frac{d V_{m}}{d m}+\frac{\cos \phi}{r_{m}}+\frac{\csc ^{2} \beta}{2}\left(\frac{1}{Q} \frac{d Q}{d r}\right)+\frac{1}{2} \frac{d\left(\cot ^{2} \beta\right)}{d r}+\frac{\cot ^{2} \beta}{r}+\frac{2 \Omega}{V_{m}} \cot \beta\right] \\
& =2 \sin ^{2} \beta\left[\frac{1}{Q} \frac{d(/ Q)}{d r}+\frac{\Omega^{2} r^{2}}{2}\left(\frac{1}{Q} \frac{d Q}{d r}\right)\right] \\
& Q=\left(p_{02} / p_{01}\right)^{(\gamma-1) / r} /\left(T_{02} / T_{01}\right)
\end{aligned}
$$

where $\mathrm{V}_{\mathrm{m}}, \beta$ and $\Phi$ are meridional flow velocity, relative flow angle and streamline slope angle, and subscripts 1 and 2 represent blade inlet and outlet.

As can be seen in equation (3), the through-flow analysis method requires flow deviation and pressure loss models. The present study uses two empirical correlations for design- and off-design points as flow deviation model, and categorizes total pressure loss into four components of blade profile, secondary flow, end-wall boundary layer and tip clearance flow and then calculates their magnitudes by using the corresponding empirical correlations and spanwise distribution model.

Flow deviation from blade outlet is assumed to be composed of the $\operatorname{design}\left(\delta_{\mathrm{des}}\right)$ and the off- 
$\operatorname{design}\left(\delta_{\text {off }}\right.$-des $)$ ones as follows:

$$
\beta_{2}=\kappa_{2, d}+\delta_{\text {des }}+\delta_{o f f-d e s}
$$

where $\beta_{2}$ and $\kappa_{2, \mathrm{~d}}$ are blade outlet flow and setting angles. Here, the flow deviation angles at design and off-design points are calculated by McKenzie's and modified Creveling's correlations $[1,4]$.

The present pressure loss models are used to calculate overall total pressure loss coefficient $\left(\omega_{\mathrm{T}}\right)$ and then actual the total pressure at blade outlet $\left(\mathrm{p}_{02 \text {,actual }}\right)$ in equations $(6)$, which is required for determining the entropy function, $\mathrm{Q}$, in equation (4).

$$
\begin{aligned}
& \Delta p_{\text {loss }}=p_{02, \text { ideal }}-p_{02, \text { actual }}=\omega_{T} \frac{1}{2} \rho_{1} V_{1}^{2} \\
& \omega_{T}=\omega_{p}+\omega_{s}+\omega_{c}+\omega_{e}
\end{aligned}
$$

Here, the pressure loss coefficients for blade profile $\left(\omega_{\mathrm{p}}\right)$, secondary flow $\left(\omega_{\mathrm{s}}\right)$, end-wall boundary layer $\left(\omega_{\mathrm{e}}\right)$ and tip clearance flow $\left(\omega_{\mathrm{c}}\right)$ in equation (7) are calculated by the empirical correlations of Koch and Smith [5], Lee and Chung [6], Howell and Fujii [7].

\section{Results and Discussions}

In order to verify the design reliability and the prediction accuracy of the present method, the present method is applied to the fan model by Hurault [8], which is designed with the tip diameter of $380 \mathrm{~mm}$, the hub-to-tip ratio of 0.46 and the RPM of 2700 . Fig. 1 shows the comparison results between the present prediction and the test results, which are in good agreements in the aspects of performance curves and velocity distributions.

- Performance curves

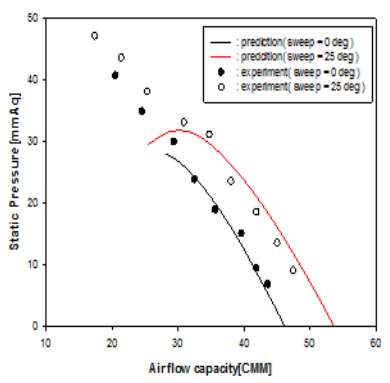

- Velocity distributions at $\mathbf{Q}=\mathbf{Q}_{\mathrm{d}}$

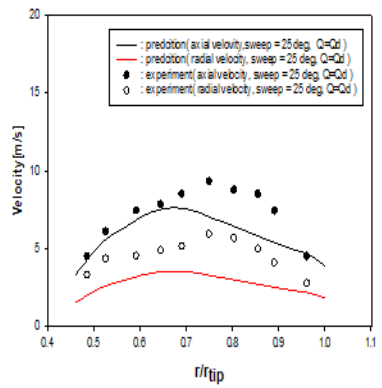

\section{- Velocity distributions at $\mathrm{Q}=1.3 \mathrm{Q}_{\mathrm{d}}$}

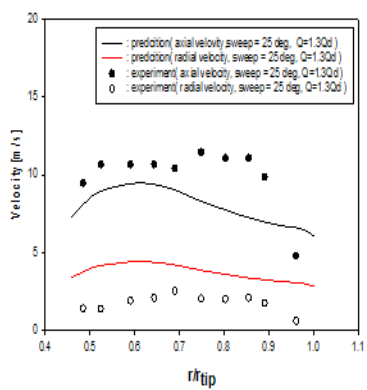

Fig. 1. Performance curves and velocity distributions of Hurault's fan model.

The present method is also applied to design a new fan model of the KoreaAmass Co., which is designed with the tip diameter of $260 \mathrm{~mm}$, the hub-to-tip ratio of 0.39 and the RPM of 1650. In addition, the new KoreaAmass fan model is also designed with forced vortex design concept. The performance prediction results by the present method are represented and compared with the test results of new and existing fan models in Figs. 2-4. As can be seen in Fig. 2, the p-Q curve prediction by the present method on new model agrees well with the test result, and the new fan model designed with combined vortex design concept gives much higher static pressure than the existing one over entire range of flow capacity. Fig. 3 shows good agreement between the prediction and the test results on the fan efficiency of new model, and also represents that the new model designed with combined vortex design concept has efficiency improvement by maximum $10 \%$ compared with the existing one. Fig. 4 shows the comparison 
results on fan power between the new and the existing models, and represent that the new model reduces power consumption by maximum $10 \mathrm{~W}$ compared with the existing one.

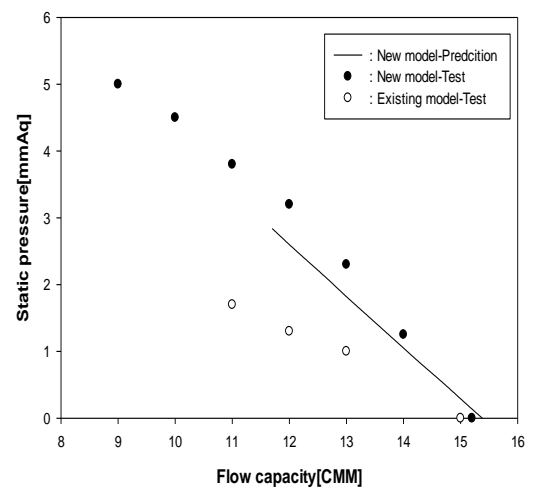

Fig. 2. P-Q curves of KoreaAmass's new and existing fan models.

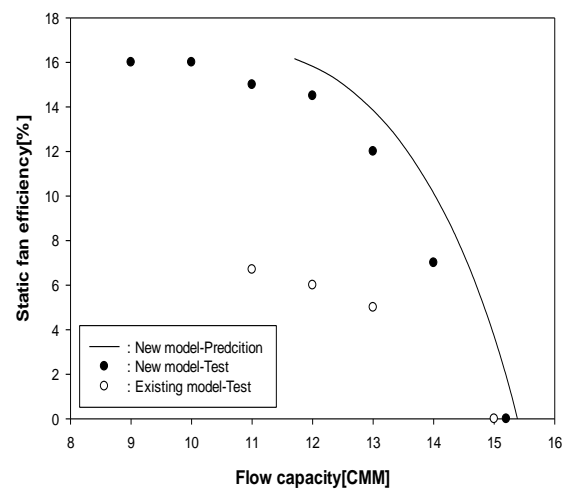

Fig. 3. Efficiency curves of KoreaAmass's new and existing fan models.

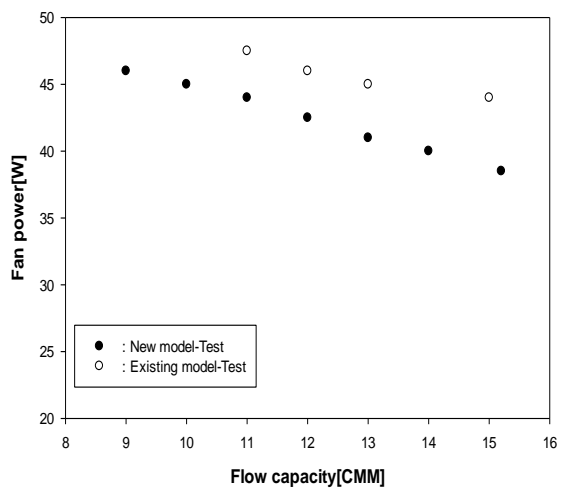

Fig. 4. Power curves of KoreaAmass's new and existing fan models.

\section{Conclusions}

The present study provides a method to design axial flow fan blade with combined vortex design concept and to predict the performance of designed fan. Fan blade design is made by applying combined vortex design concept to cascade theory, and fan performance prediction is conducted by using the through-flow analysis method with flow deviation and pressure loss models. The fan performance prediction results by the present method are well agreed with test results, so the present method is 
considered to be very suitable at actual design practice. In addition, the present study also shows that fan model designed with combined vortex design concept can give much higher pressure and efficiency, and lower power consumption than the existing ones. From these research results, the present design method can be effectively used in energy-saving fan design practice.

\section{Acknowledgement}

This research is supported by the research grant of the Small and Medium Business Administration of Korea, 2016.

\section{References}

[1] Dixon SL. Fluid Mechanics and Thermodynamics of Turbomachinery, $4^{\text {th }}$ ed., Butterworth \& Heinemann, 1998

[2] Lewis RI. Turbomachinery Performance Analysis, Arnold, 1996

[3] Novak RA. Streamline curvature computing procedure for fluid flow problems. ASME Journal of Eng. For Power, 1967; 89:487-490.

[4] Olivier A, Olivier L. A quasi-one dimensional model for axial compressors, ISABE 2005 Proceedings, 2005

[5] Koch CC, Smith Jr LH. Loss sources and magnitudes in axial-flow compressors. ASME J. of Eng. for Power, 1976; 98:411424.

[6] Lee C, Chung MK. Secondary flow loss and deviation models for through-flow analysis of axial flow turbomachinery. Mechanics Research Communications, 1991:403-408.

[7] Horlock JH, Lakshminarayana B. Secondary flows: theory, experiment and applications in turbomachinery aerodynamics. Annual Review of Fluid Mechanics, 1973; 5:247-280.

[8] Hurault J, Kouidri S, Bakir F. Experimental and numerical study of the sweep effect on three-dimensional flow downstream of axial flow fans. Flow Measurement \& Instrumentation, 2010; 21:155-165. 